\title{
Template-Directed Directionally Solidified 3D Mesostructured AgCl-KCl Eutectic Photonic Crystals
}

\author{
Jinwoo Kim, Larry K. Aagesen, Jun Hee Choi, Jaewon Choi, Ha Seong Kim, Jinyun Liu, \\ Chae-Ryong Cho, Jin Gu Kang, Ali Ramazani, Katsuyo Thornton,* and Paul V. Braun*
}

\begin{abstract}
3D structured materials with characteristic dimensions on the order of the wavelength of light offer opportunities for sensors, ${ }^{[1,2]}$ solar-energy harvesting, ${ }^{[3-5]}$ light-emitting diodes, ${ }^{[6]}$ and when the structure can be controlled to subwavelength dimensions, optical metamaterials. ${ }^{[7,8]}$ Current approaches to construct deterministically mesostructured materials include phase-mask lithography, ${ }^{[9,10]}$ colloidal self-assembly, ${ }^{[11,12]}$ two-photon polymerization, ${ }^{[13,14]}$ and direct-ink writing. ${ }^{[15,16]}$ Of the numerous methods available, 3D colloidal templating methods and phasemask lithography offer the easiest path to large area structures, as they form the complete 3D structure in a single self-assembly (colloidal templating) or lithographic (phase-mask lithography) step. The resultant template can then be converted into a diverse set of both single and polycrystalline materials, including $\mathrm{Si}^{,[17]}$ $\mathrm{GaAs}^{,[6]}$ and $\mathrm{Cu}_{2} \mathrm{O},{ }^{[18,19]}$ via both solution-based electrodeposition and gas phase chemical vapor deposition methods. However, it remains challenging to create the large volumes of complex structures with characteristic dimensions below $\approx 500 \mathrm{~nm}$ required for some applications for optical metamaterials.

A unique opportunity for forming structured optical materials is offered by eutectic solidification, the result of which can be a highly organized, multiphase, structured material. ${ }^{[20-22]}$ Eutectic microstructures can be periodic or aperiodic, with characteristic dimensions ranging from tens of nanometers to hundreds of micrometers, ${ }^{[23,24]}$ depending on the materials and solidification conditions, and when directionally solidified, can exhibit long-range order. ${ }^{[25]}$ Eutectics based on insulators, semiconductors, metals, and organic compounds are all known, providing a wide range of properties that can be exploited. As
\end{abstract}

Dr. J. Kim, Dr. J. H. Choi, Dr. J. Choi, H. S. Kim, Dr. J. Liu, Prof. C.-R. Cho, J. G. Kang, Prof. P. V. Braun Department of Materials Science and Engineering Frederick Seitz Materials Research Laboratory University of Illinois at Urbana-Champaign

Urbana, IL 61801, USA

E-mail: pbraun@illinois.edu

Dr. L. K. Aagesen, Dr. A. Ramazani, Prof. K. Thornton

Department of Materials Science and Engineering

University of Michigan

Ann Arbor, MI 48109, USA

E-mail: kthorn@umich.edu

Dr. J. H. Choi

Samsung Advanced Institute of Technology

Samsung Electronics

Suwon 443-803, South Korea

Prof. C.-R. Cho

Department of Nanoenergy Engineering

Pusan National University

Busan 609-735, South Korea

DOI: 10.1002/adma.201502265
Pawlak et al. first suggested, an appropriate eutectic system could even serve as an optical metamaterial. ${ }^{[26-30]}$ Here, we show through both modeling and experiment, that the combination of the characteristic periodic structure of a 3D colloidal template, and the native self-organizing structure of a eutectic system, leads to the emergence of an optically active 3D mesostructured photonic crystal that is both more complex than that of either the template or the unconstrained eutectic and can exhibit structure at length scales much smaller than that of the template.

There are many aspects to consider in the selection of an appropriate photonically active eutectic system. For many photonic crystal applications, periodic structures are preferred, and only a select number of eutectic mixtures solidify into periodic structures rather than more disordered structures, although there are a number of interesting possibilities for disordered photonic glasses. ${ }^{[31,32]}$ It is important that the template (i.e., a silica opal) be thermally and chemically stable against the eutectic melt, and that the eutectic melt flows into the template. Most metals have high surface tensions, and thus are difficult to flow into the porous structure of the template. Finally, it is highly desirable that one of the two phases of the eutectic can be selectively removed to increase the refractive index contrast, which would also enable a different material to be infilled into the structure (e.g., silver, to form a metallodielectric structure). Consideration of all these factors led us to eutectic salts. Fluoride based eutectics, e.g., $\mathrm{LiF}-\mathrm{CaF}_{2}$, form highly regular structures, and have been considered as photonic materials, ${ }^{[3]}$ however, they react with a silica template. We find the AgCl-KCl eutectic system meets all the requirements (the $\mathrm{KCl}$ phase can be selectively etched by water). Using known physical parameters of the AgCl-KCl eutectic, we studied the effect of the template on the solidifying eutectic's mesostructure using a phase field model. Because both $\mathrm{AgCl}$ and $\mathrm{KCl}$ are transparent in the visible and IR, the optical properties of both the untemplated and the templated eutectic structure could be investigated.

Scheme 1 shows the key steps in the fabrication of the colloidal crystal templated $\mathrm{AgCl}-\mathrm{KCl}$ eutectic and the final mesostructured $\mathrm{AgCl}$ inverse opal after removal of the $\mathrm{KCl}$ phase and the silica template. A silica opal was formed on a substrate via a doctor-blade method. The resultant opal-coated substrate was placed at a $45^{\circ}$ angle on a stainless holder. $\approx 0.05 \mathrm{~g}$ of the $\mathrm{AgCl}-\mathrm{KCl}$ eutectic powder $(70 \mathrm{~mol} \% \mathrm{AgCl}$ and $30 \mathrm{~mol} \% \mathrm{KCl}$ ), was placed on the top edge of the template. The sample was heated to $450{ }^{\circ} \mathrm{C}$ for $60 \mathrm{~min}$ in air. The $\mathrm{AgCl}-\mathrm{KCl}$ eutectic melts (eutectic temperature, $T_{\mathrm{E}}=318{ }^{\circ} \mathrm{C}$ ), and flows into the porous silica colloidal crystal through a combination of capillary force and gravity, wetting the opal up to its top (Scheme 1c). The porous $\mathrm{AgCl}$ inverse opal structure was obtained by dissolution 


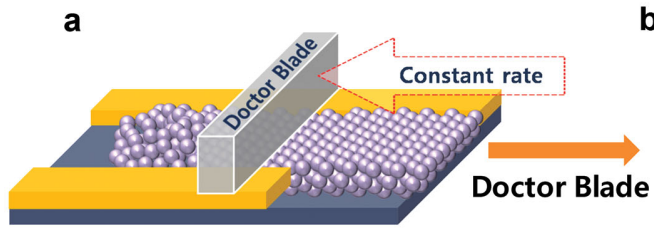

b

Silica opal template
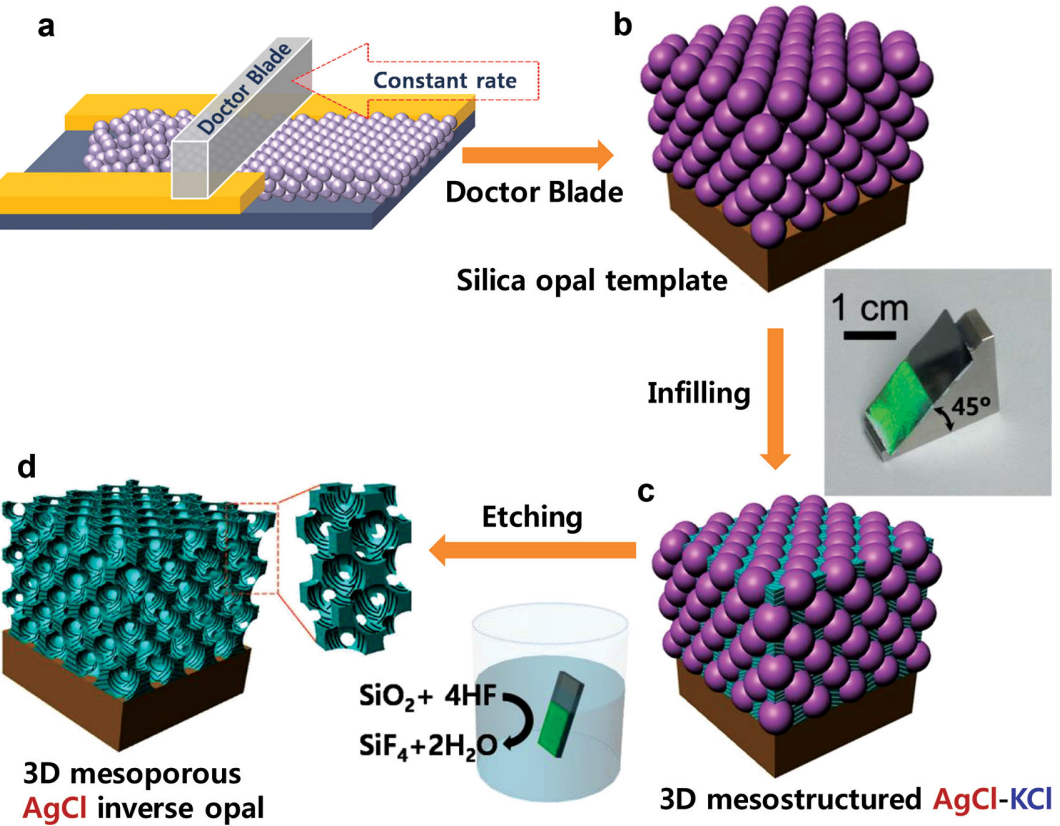

Scheme 1. Key steps for fabrication of $3 \mathrm{D}$ mesostructured $\mathrm{AgCl}-\mathrm{KCl}$ and $3 \mathrm{D}$ mesoporous $\mathrm{AgCl}$ inverse opal structure. a) Doctor-blade method used to assemble the $6 \mu \mathrm{m}$ diameter colloida particles into the silica opal template illustrated in (b). c) The $\mathrm{AgCl}-\mathrm{KCl}$ eutectic filled silica colloidal template (photograph shows an opal formed from $500 \mathrm{~nm}$ diameter silica colloids on a substrate sitting on the support block). d) 3D mesoporous $\mathrm{AgCl}$ inverse opal formed by dissolution of the silica colloidal template and $\mathrm{KCl}$ with $5 \% \mathrm{HF}$ (aq) followed by DI water.
Information) confirms the lighter phase is $\mathrm{AgCl}$, and the darker is $\mathrm{KCl}$. Figure 1c,d shows plan and cross-sectional view SEM images of the porous $\mathrm{AgCl}$ lamellar structure after dissolution of the $\mathrm{KCl}$ phase in DI water for $5 \mathrm{~min}$. The $\mathrm{AgCl}-\mathrm{KCl}$ eutectic is known to exhibit extremely low mutual solubilities, ${ }^{[34]}$ and pure $\mathrm{AgCl}$ has a very low solubility in water $\left(\approx 500 \mu \mathrm{g} / 100 \mathrm{~g}\right.$ at $\left.50{ }^{\circ} \mathrm{C}\right)$. $\lambda_{\mathrm{AgCl}}$ of the lamellar $\mathrm{AgCl}$ is $\approx 350 \mathrm{~nm}$, and the surface of the $\mathrm{AgCl}$ appears smooth. EDX confirms the absence of $\mathrm{K}$, supporting the hypothesis that the $\mathrm{KCl}$ phase was selectively removed (Figure S3b, Supporting Information).

The optical properties of as-solidified eutectic were probed by collecting reflectance using a Fourier-transform infrared (FTIR) spectrometer microscope, and the reflectance spectra were compared with finite-difference time domain (FDTD) simulations. As shown in Figure S5a (Supporting Information), the $\approx 4 \mathrm{~mm}$ thick eutectic sample was polished and oriented such that the incident beam is normal to the eutectic layers. Figure 1e presents normal-incidence reflectance of the air-cooled eutectic (lower panel) and an FDTD simulation (upper panel) of the structure. The FDTD simulation uses the SEMmeasured $\lambda$ from the eutectic, Figure 1f, of the silica colloidal template and $\mathrm{KCl}$ with $5 \% \mathrm{HF}$ (aq) followed by a DI water rinse (Scheme $1 \mathrm{~d}$ ).

Figure 1a,b presents scanning electron microscopy (SEM) images of plan and cross-sectional views of a solidified AgCl$\mathrm{KCl}$ eutectic template-free control sample that was air cooled at about $7^{\circ} \mathrm{C} \mathrm{min}^{-1}$, showing the expected lamellar sub-micrometer structure. The thicknesses of the $\mathrm{AgCl}$ lamellae $\left(\lambda_{\mathrm{AgCl}}\right)$ (bright in the SEM image) are around $380 \mathrm{~nm}$ and the thicknesses of the $\mathrm{KCl}$ lamellae $\left(\lambda_{\mathrm{KCl}}\right)$ (dark in the SEM image) are around $260 \mathrm{~nm}$. It can be noted in the cross section that $\lambda_{\mathrm{AgCl}}$ and $\lambda_{\mathrm{KCl}}$ tend to be slightly larger in the interior than on the surface because $\lambda$ tends to increase with decreasing cooling rate and the interior of the sample solidifies more slowly than the surface. A small degree of faceting is observed in the $\mathrm{KCl}$ phase (Figure S1, Supporting Information), which may be expected based on the work of Hunt and Jackson. ${ }^{[20,30]} \mathrm{AgCl}$ has relatively low melting entropy, $\Delta S=16.85 \mathrm{~J} \mathrm{~K}^{-1} \mathrm{~mol}^{-1}$, or dimensionless melting entropy of $X=\Delta S / G_{\mathrm{g}}=2.02$, where $G_{\mathrm{g}}=$ gas constant. On the other hand, $\mathrm{KCl}$ has a melting entropy of $25.03 \mathrm{~J} \mathrm{~K}^{-1} \mathrm{~mol}^{-1}$, or $X=3.01$. When $X$ is greater than about 2 , faceting can be expected, suggesting that $\mathrm{KCl}$ will grow as a faceted phase.

The composition of the eutectic was confirmed by X-ray diffraction (XRD), where sharp peaks for both $\mathrm{AgCl}$ and $\mathrm{KCl}$ are observed (Figure S2, Supporting Information), and energy dispersive X-ray spectroscopy (EDX), where peaks associated with Ag, Cl, and K are observed (Figure S3, Supporting Information). No XRD peaks corresponding to elemental Ag were discerned, even though $\mathrm{AgCl}$ can convert to $\mathrm{Ag}$ under visible and UV light illumination. Combination of the SEM images, the EDX spectra, and EDX mapping (Figure S4, Supporting and the refractive indices of $\mathrm{KCl}$ and $\mathrm{AgCl}, 1.49$ and 2.09, respectively, as input parameters. In the measured reflection spectra (black line), first- and second-order reflection peaks were observed at $\approx 2.37 \mu \mathrm{m}(420 \mathrm{~nm}$ FWHM) and $\approx 1.23 \mu \mathrm{m}$ (70 nm FWHM) which agree with the FDTD simulations and that expected from a 1D photonic crystal, which will exhibit a set of stop bands at frequencies $\omega, \omega / 2, \omega / 3$, and so on. ${ }^{[35]}$ The presence of the small reflectance peak at $\approx 1.65 \mu \mathrm{m}$, which was not observed in the FDTD simulations (or in all samples) may be due to some degree of disorder in the eutectic structure. The experimental reflectance is less than the calculated intensity as is commonly observed in self-organized photonic structures (e.g., colloidal crystals), due to various forms of disorder.

Figure 2a,b presents a representative cross-sectional and plan view SEM images of an AgCl-KCl eutectic infilled and solidified in colloidal crystal template formed from $6 \mu \mathrm{m}$ diameter silica particles. Due to rapid sedimentation under gravity, the $6 \mu \mathrm{m}$ diameter colloidal particles were assembled via a doctorblading method (Figure S6, Supporting Information) rather than more conventional evaporation-based colloidal crystallization methods. ${ }^{[36]}$ As shown in Figure 2a,b, the template was successfully filled with void free $\mathrm{AgCl}-\mathrm{KCl}$ eutectic by capillary wetting. As shown in Figure S7 (Supporting Information), no significant cracking was observed over large areas, suggesting capillary wetting alone (no applied pressure) may be sufficient for infiltration of large-area opals. Typical dimensions of the fabricated samples were $1.5 \times 2 \mathrm{~cm}$.

A unique and unexpected mesostructure is observed in the eutectic phase inside the silica opal template. Unlike the lamellar structure of the bulk AgCl-KCl eutectic (Figure 1), 

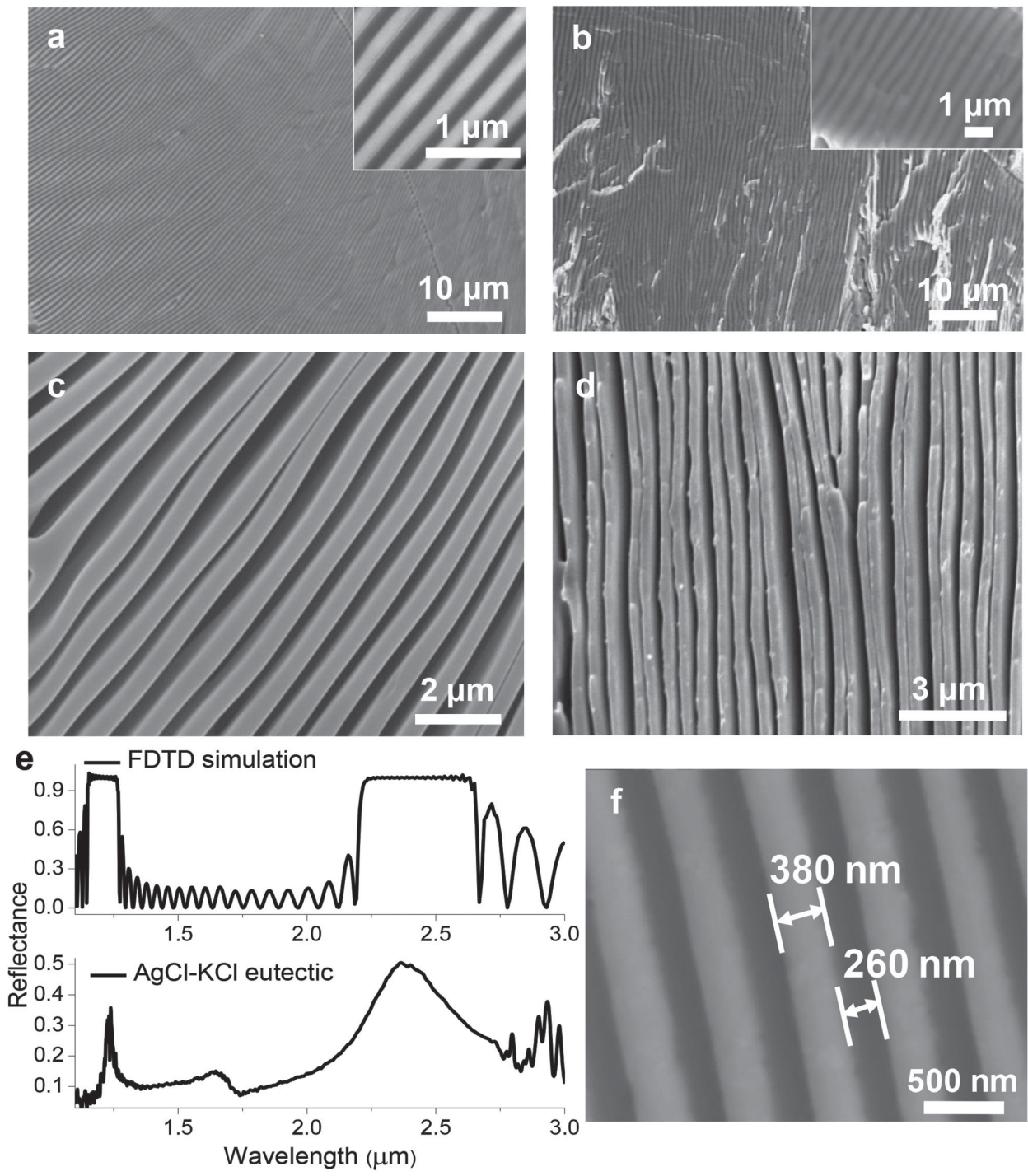

Figure 1. SEM images of a) plan and b) cross-sectional views of as-melted and air-cooled $\mathrm{AgCl}$ (bright)-KCl (dark) eutectic. SEM images of c) plan and d) cross-sectional views of the eutectic after selective $\mathrm{KCl}$ removal with DI water. e) FDTD simulated (upper panel), and experimentally measured (lower panel) reflectance from the $\mathrm{AgCl}-\mathrm{KCl}$ eutectic shown in the cross-sectional SEM image in (f).

complex self-organized "wavy" structures were observed inside the template. Because of the similar thermal conductivity of silica template $\left(\approx 1.4 \mathrm{~W} \mathrm{~m}^{-1} \mathrm{~K}^{-1}\right)$ to the thermal conductivity of $\mathrm{KCl}\left(\approx 1.14 \mathrm{~W} \mathrm{~m}^{-1} \mathrm{~K}^{-1}\right)$ and $\mathrm{AgCl}\left(\approx 1.15 \mathrm{~W} \mathrm{~m}^{-1} \mathrm{~K}^{-1}\right)$ and the much higher thermal conductivity of the Si substrate $\left(\approx 150 \mathrm{~W} \mathrm{~m}^{-1} \mathrm{~K}^{-1}\right)$, we suspect that eutectic solidification initiates at the substrate and propagates upward through the template, where it encounters the colloidal particles, resulting in the observed wavy structure. An SEM image of a partially infilled silica template (Figure $2 \mathrm{c}$ and the inset of Figure 2c) supports this hypothesis, and appears to show the eutectic first initiating at the substrate with the expected lamellar structure, followed by the disruption of the lamellae as they encounter the template. After cooling, both the silica colloidal crystal template and $\mathrm{KCl}$ phase can be selectively removed by sequential dissolution in 5\% HF (aq) and DI water, forming the 3D mesoporous inverse $\mathrm{AgCl}$ opal structure shown in Figure 2d. As shown in the inset of Figure 2d, a rather complex porous $\mathrm{AgCl}$ mesostructure containing features with characteristic dimensions of 100-200 nm is observed. As expected, EDX (Figure S8, Supporting Information) confirms removal of both $\mathrm{KCl}$ and the silica template.

To understand the effect of 3D template-induced confinement on mesostructure development during eutectic solidification, the $\mathrm{AgCl}-\mathrm{KCl}$ eutectic was embedded in 3D templates formed from colloids with various diameters. Figure 3 shows cross-sectional SEM images of the eutectic infilled in templates formed from $500 \mathrm{~nm}, 2 \mu \mathrm{m}$, and $6 \mu \mathrm{m}$ colloidal particles. Since the capillary-wetting method of infilling the template does not result in an overlayer, extra $\mathrm{AgCl}-\mathrm{KCl}$ eutectic powder was placed on top of the sample prior to heating and cooling to generate an overlayer. This enabled determination of the native periodicity of the eutectic under the experimental solidification conditions. The morphology of eutectic within 

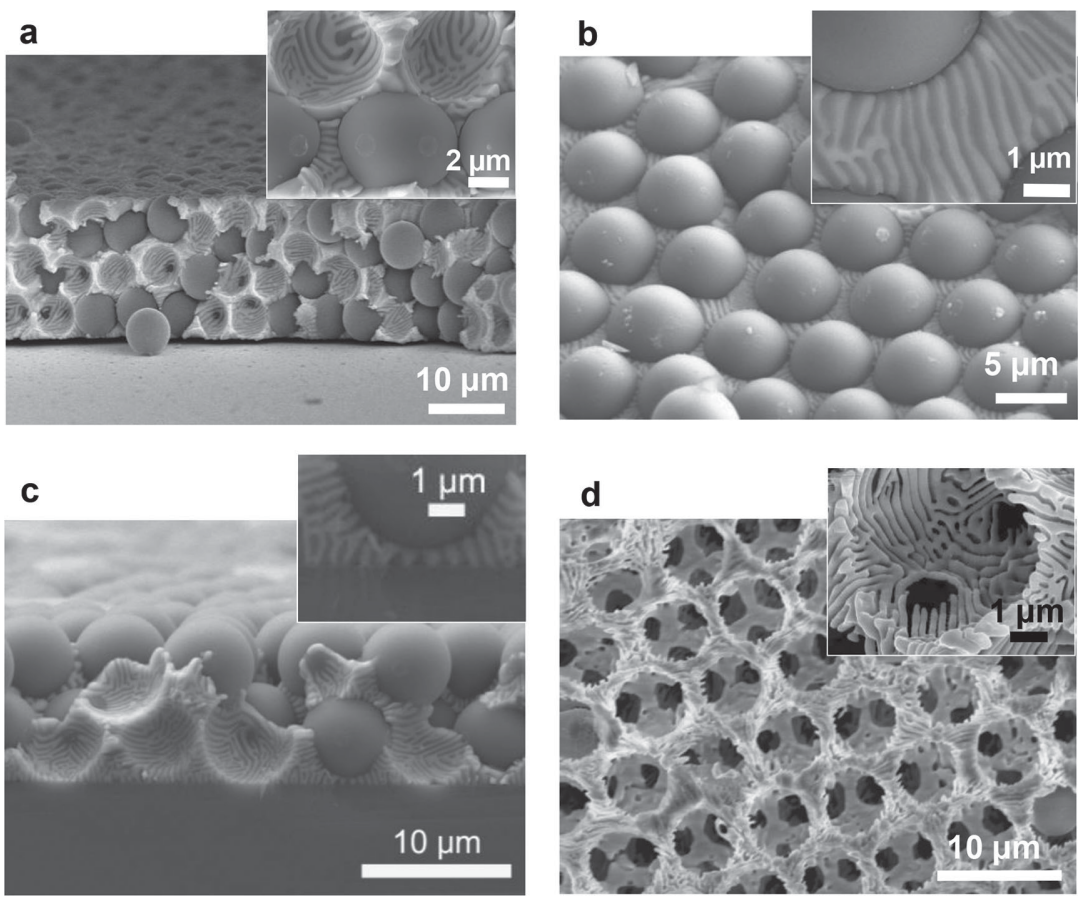

Figure 2. SEM images of the air-cooled $\mathrm{AgCl}-\mathrm{KCl}$ eutectic templated by the $6 \mu \mathrm{m}$ diameter colloid template. Representative a) cross-sectional and b) plan view SEM images. Inset of (a) shows complex self-organized "wavy" structures inside the template and the inset of (b) exhibits the lamellar structure formed between silica particles on top of the template. c) A partially infilled template. The inset shows the eutectic first initiating at the substrate with the expected lamellar structure, and then the lamellae change direction. d) The mesostructured $\mathrm{AgCl}$ inverse opal formed by $\mathrm{HF}$ and $\mathrm{DI}$ water etching of the silica and $\mathrm{KCl}$. Inset: Higher magnification view.

the template was found to depend greatly on the diameter of interstitial site of colloidal template. A wavy yet still locally lamellar structure which attempts to follow the curvature of colloidal surface was observed within the $6 \mu \mathrm{m}$ template, whereas what appears to be a nearly random agglomerate of both phases was observed in the $500 \mathrm{~nm}$ and $2 \mu \mathrm{m}$ templates. Within a $3 \mu \mathrm{m}$ template, the eutectic structure starts to form a lamellar-like structure, however overall, it is rather disordered (Figure S9, Supporting Information). Lamellar structures selforganize by coupled growth as the two phases simultaneously grow into the melt. ${ }^{[20,30,37]}$ During solidification, the eutectic structure would prefer to be lamellar with some characteristic layer thicknesses. However, in the presence of the template, the lamellar growth is physically restricted because the diameters of the pores within the template are on the order of the lamella thickness or smaller. The diameters of the pores in the closepacked planes of the colloidal crystal, defined as the diameter of a circle that would fit in the open space at the contact of three colloidal particles, are as follows: $6 \mu \mathrm{m}$ diameter colloids, $928 \mathrm{~nm} ; 3$ m diameter colloids, $464 \mathrm{~nm}$; $2 \mu \mathrm{m}$ diameter colloids, $310 \mathrm{~nm}$; and $500 \mathrm{~nm}$ diameter colloids, $77 \mathrm{~nm}$. The necks (the opening at the contact of three spheres) in the pore structure have a significant effect on the solidified eutectic structures. In the smaller templates, they appear to prevent self-organization; in the larger templates, they greatly distort the lamellar structure. The pitch (center-to-center spacing of one phase) of the lamellar $\mathrm{KCl}-\mathrm{AgCl}$ eutectic is about $640 \mathrm{~nm}$ under the As the removal rate increased, the optical properties changed. Normal-incidence transmission spectra of the templated air cooled solidified sample showed a sharp transmission dip (a stop band) at $1.42 \mu \mathrm{m}$. When the pulling rate was $70 \mu \mathrm{m} \mathrm{s}^{-1}$, the transmission dip was at $1.18 \mu \mathrm{m}$, and when the pulling rate was $100 \mu \mathrm{m} \mathrm{s}^{-1}$, the transmission dip was at $690 \mathrm{~nm}$. All samples showed large $\mathrm{AgCl}$ band-edge absorption at $\approx 410 \mathrm{~nm}$. All observed optical features were from the eutectic structures. Optical features of $6 \mu \mathrm{m}$ colloidal template would be much deeper in the IR. The optical properties of the sample pulled at $100 \mu \mathrm{m} \mathrm{s}^{-1}$ were simulated using FDTD based on the SEMdetermined layer thicknesses. The simulation assumed alternating $90 \mathrm{~nm} \mathrm{KCl}$ and $100 \mathrm{~nm} \mathrm{AgCl}$ layers embedded within a five-layer close-packed $6 \mu \mathrm{m}$ colloid diameter opal template. As shown in Figure 4e, the FDTD simulation generates a transmission dip at $680 \mathrm{~nm}(130 \mathrm{~nm}$ FWHM), which generally matches the experimental transmittance, showing that the lamellar structure will retain strong optical features, even when perforated with a periodic array of large voids.

As a first step to a predictive design process, the templatedirected air-cooled solidification of $\mathrm{AgCl}-\mathrm{KCl}$ eutectic was simulated using a phase field model modified by the smoothed boundary method to include the template (see the Experimental Section for details of the model). Lamellae with a pitch of $640 \mathrm{~nm}$ (similar to that observed for the air-cooled samples) were solidified into face-centered cubic (fcc)-ordered colloidal crystals constructed from spheres with diameters of 453, 906, 

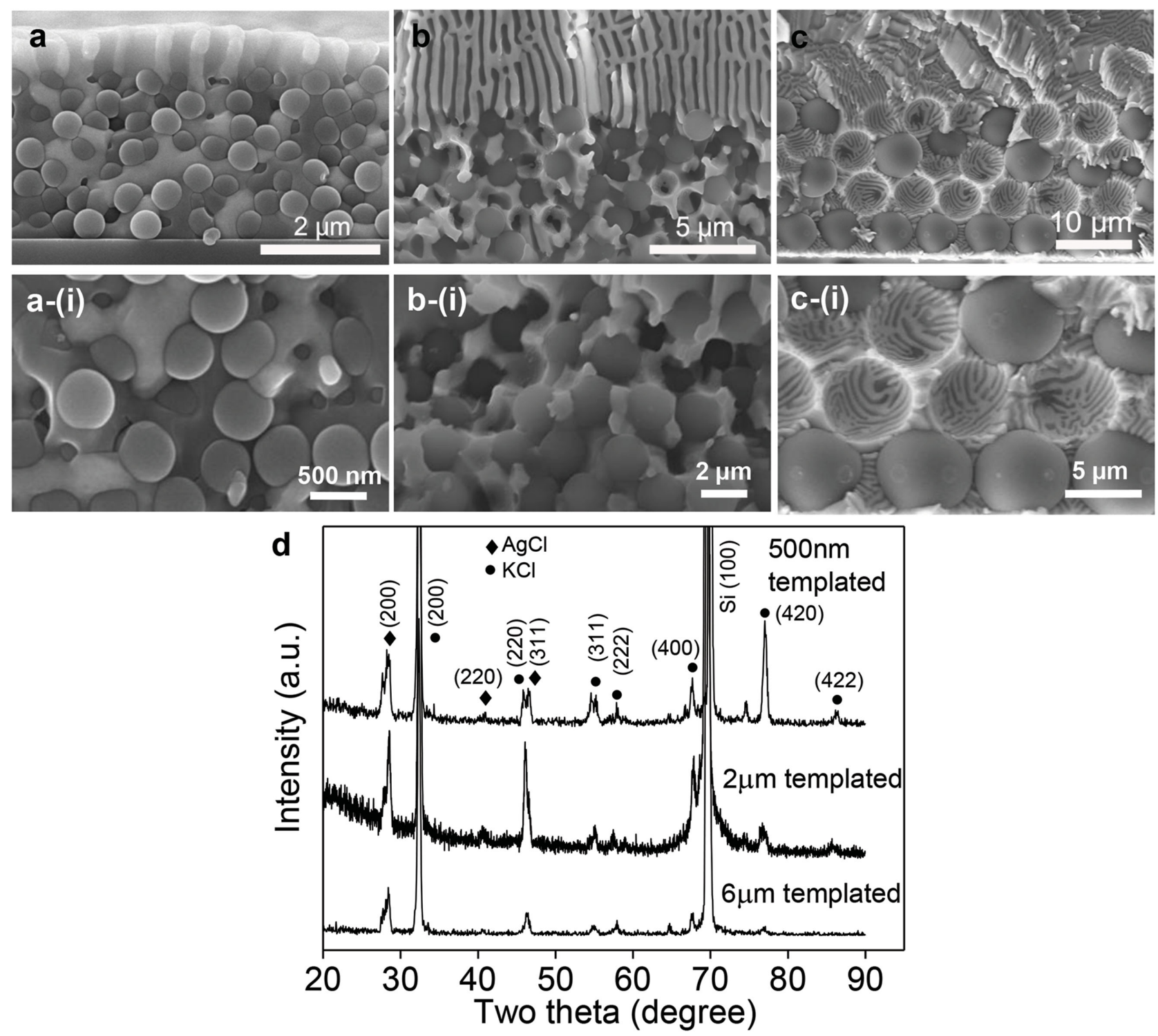

Figure 3. Cross-sectional SEM images of air-cooled templated eutectic in a) $500 \mathrm{~nm}$, b) $2 \mu \mathrm{m}$, and c) $6 \mu \mathrm{m}$ silica opal templates. a-(i)-c-(i) Higher magnification SEM images of the templated eutectics shown in (a)-(c). d) $2 \theta / \omega$ X-ray diffraction scans of the $500 \mathrm{~nm}, 2 \mu \mathrm{m}$, and $6 \mu \mathrm{m}$ colloid templated eutectic samples.

and $1360 \mathrm{~nm}$ (see Figure 5). The $453 \mathrm{~nm}$ diameter spheres were chosen to be similar to the $500 \mathrm{~nm}$ diameter colloids used in the experiment, as well as to set the fcc unit cell size in the $x$-direction equal to the $640 \mathrm{~nm}$ eutectic spacing. This allows the use of a single fcc unit cell (with periodic boundary conditions in the $x$ and $z$-directions) to represent a system infinite in extent in $x$ and $z$. Due to computational resource limitations, the larger diameter colloid experimental systems could not be directly simulated, but the effects of increasing colloidal diameter can be qualitatively understood by comparison of simulations of solidification into colloidal crystals constructed from $906 \mathrm{~nm}$ diameter spheres (two lamellar periods in the $x$-direction) and $1360 \mathrm{~nm}$ spheres (three lamellar periods in the $x$-direction).

In Figure 5, it can be seen that, although phase separation is still observed as the $\mathrm{AgCl}$ and $\mathrm{KCl}$ lamellae enter the template, the lamellar structure is greatly modified by the template. Interestingly, for the smallest diameter sphere template, small $\mathrm{KCl}$ regions that are not connected to the original $\mathrm{KCl}$ forms (blue circled regions in Figure $5 b$ ). This is in contrast to the larger diameter sphere templates (Figure $5 c-f$ ), where both phases are continuous (confirmed by visualizing the $\mathrm{KCl}$ phase alone). In this case, as the eutectic enters the template region, the eutectic phases begin to curve around the holes formed at points of contact between the template spheres (these lamellae are shown in blue circled regions in Figure 5d,f). This curving of the eutectic microstructure may be the cause of the experimentally observed microstructure in which lamellar features curve in varying directions around each sphere. As the solidification progresses through the layers of the fcc-ordered template, the microstructure may continue to become more complex. 

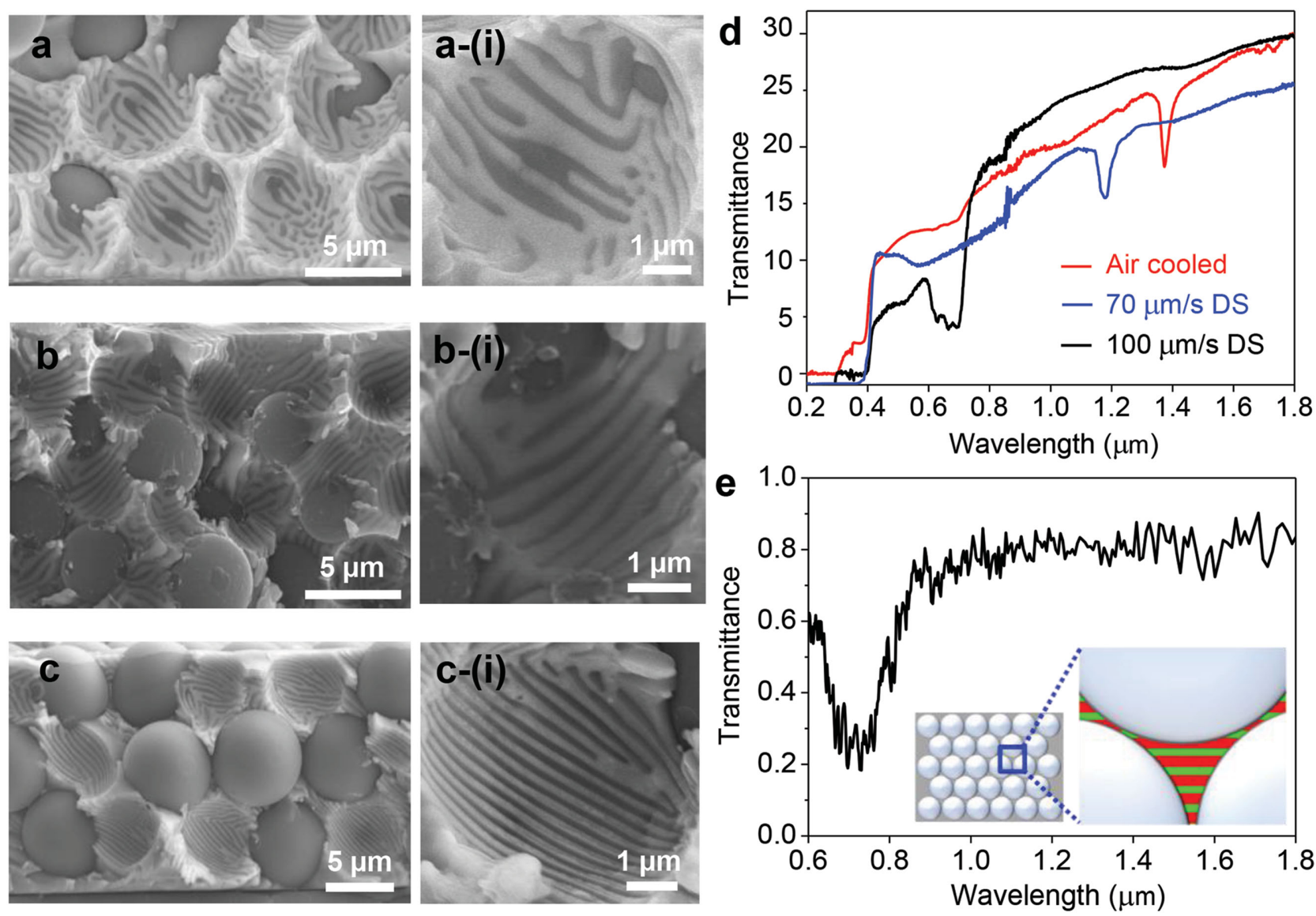

Figure 4. Directionally solidified (DS) samples (6 $\mu \mathrm{m}$ diameter silica colloid template). a) Air-cooled solidification, b) $70 \mu \mathrm{m} \mathrm{s} \mathrm{s}^{-1}$ pulling rate, and c) $100 \mathrm{um} \mathrm{s}^{-1}$ pulling rate. a-(i)-c-(i) Higher magnification SEM images of the samples shown in (a)-(c). d) Transmission spectra of air-cooled solidification (red line), $70 \mu \mathrm{m} \mathrm{s}^{-1}$ (blue line), and $100 \mu \mathrm{m} \mathrm{s}^{-1}$ (black line) pulling rate. e) FDTD simulation of the optical transmission of a structure formed of alternating $90 \mathrm{~nm}$ thick $\mathrm{KCl}$ and $100 \mathrm{~nm}$ thick AgCl layers formed within a five-layer template comprised of $6 \mu \mathrm{m}$ diameter silica colloids (matching the structure observed in (c-(i))). The inset shows a slice of the (111) plane of the unit cell of the structure used for FDTD simulation (green: $\mathrm{KCl}$, red: $\mathrm{AgCl}$ ).

In summary, we have observed the emergence of complex 3D mesostructures, including structures not present in either the native eutectic or the colloidal template, when a simple lamellar eutectic system solidifies within the constraints of a 3D template. Phase field modeling also shows the emergence of morphologies with structural elements quite different from those present in either the base eutectic or the colloidal template. The specific system selected, an $\mathrm{AgCl}-\mathrm{KCl}$ eutectic embedded in a silica opal template, has a number of experimental advantages, and will serve as the basis for continued study, including the effect of growth through many sphere layers. Our findings demonstrate that 3D template confinement induces complex structures, which may have interesting optical properties. This approach may be applicable for generating a variety of previously unobtainable 3D structures for optical materials and beyond, and the results here will hopefully stimulate work on such systems.

\section{Experimental Section}

$\mathrm{AgCl}-\mathrm{KCl}$ Eutectic Synthesis: The starting eutectic composition was 70 $\mathrm{mol} \% \mathrm{AgCl}, 30 \mathrm{~mol} \% \mathrm{KCl}$. High purity AgCl (99.99\%, Sigma-Aldrich) and $\mathrm{KCl}\left(99.99 \%\right.$, Sigma-Aldrich) powders were dried at $90{ }^{\circ} \mathrm{C}$ for $3 \mathrm{~h}$ and then mixed with alumina pestle in an alumina mortar at room temperature. The eutectic powder was placed on the top edge of the template and then the sample was heated to $450{ }^{\circ} \mathrm{C}$ for $60 \mathrm{~min}$ in air. The AgCl- $\mathrm{KCl}$ eutectic melts $\left(T_{\mathrm{E}}=318{ }^{\circ} \mathrm{C}\right)$, and flows into the porous silica colloidal crystal through a combination of capillary force and gravity, filling the opal right up to the top.

Opal Template Fabrication: $500 \mathrm{~nm}$ diameter silica colloids (synthesized following ref. [38] were dispersed in 200 proof ethanol to prepare an $\approx 3 \mathrm{wt} \%$ suspension and $2 \mu \mathrm{m}$ diameter silica colloids (Fiber Optic Center, Inc.) were dispersed in 200 proof ethanol to prepare an $\approx 6 \mathrm{wt} \%$ suspension. Si or glass substrates were placed at a $30^{\circ}$ angle in a $20 \mathrm{~mL}$ glass scintillation vial containing the colloidal suspension and held at $33-37{ }^{\circ} \mathrm{C}$. The colloidal crystal grew on the substrate as the ethanol evaporated. 3 and $6 \mu \mathrm{m}$ diameter silica colloids (Fiber Optic Center, Inc.) were dispersed in 200 proof ethanol to prepare an $\approx 25 \mathrm{wt} \%$ suspension. This silica suspension was subsequently cast on an Si substrate using a $90^{\circ}$ beveled doctor blade held $\approx 80 \mu \mathrm{m}$ above the top of the substrate by an $\approx 80 \mu \mathrm{m}$ thick Kapton polyimide film spacer. The doctor blade was pulled by a syringe pump at $\approx 250 \mu \mathrm{m} \mathrm{s}^{-1}$, coating the substrate with a uniform layer of the colloidal suspension. The sample was then dried in air. Representative SEM images of the $6 \mu \mathrm{m}$ silica opal template formed via the doctor-blading process are presented in Figure S6 (Supporting Information). 

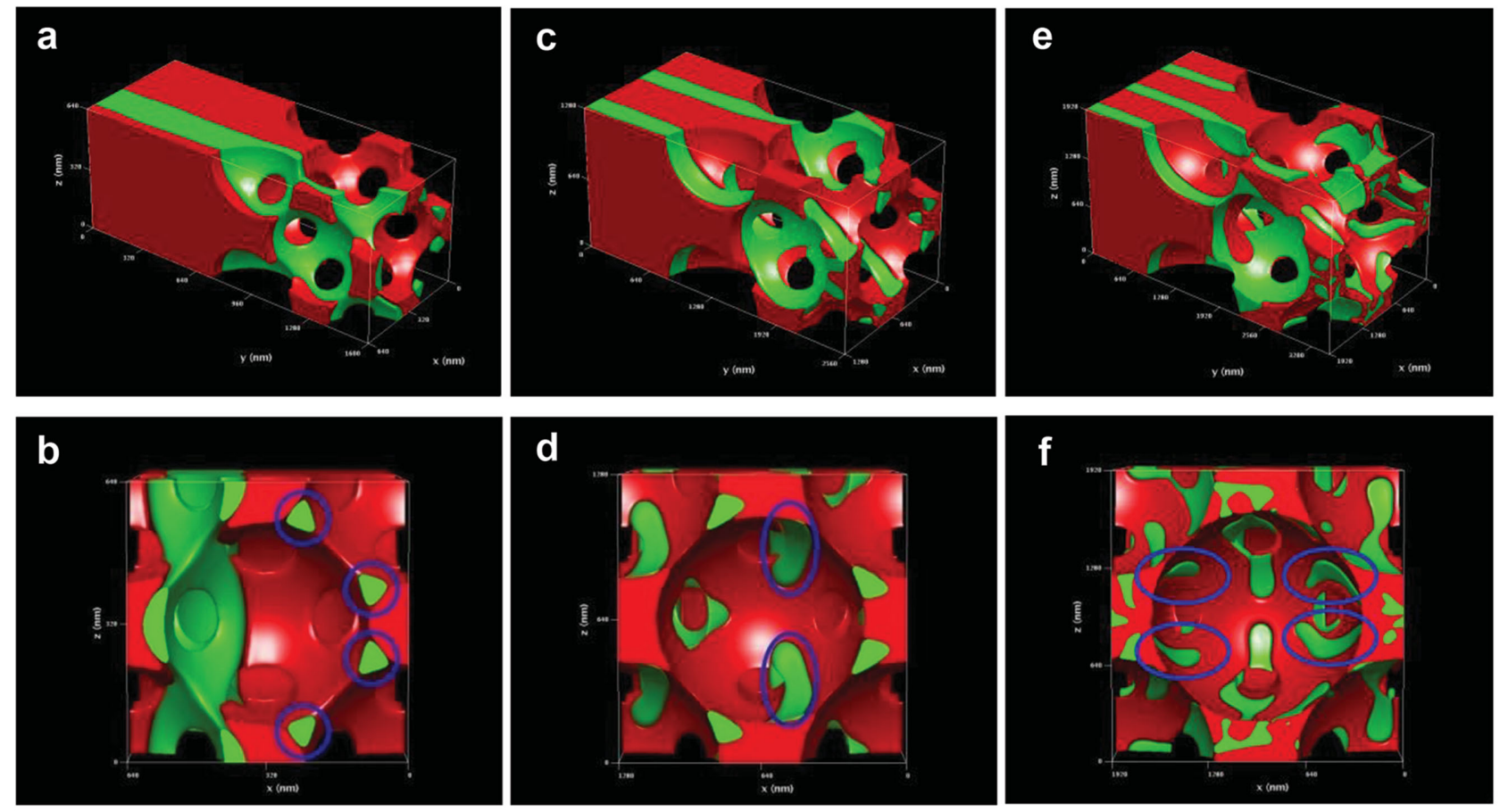

Figure 5. Phase field modeling of template-directed eutectic solidification. Solidification of AgCl-KCl lamellae into FCC-ordered spheres with diameters of a,b) 453, c,d) 906 , and e,f) $1360 \mathrm{~nm}$. AgCl is shown in red, $\mathrm{KCl}$ is shown in green, and the spheres are transparent to aid in visualization of the $\mathrm{AgCl}-\mathrm{KCl}$ microstructure. Small holes are observed at the contact points between spheres. In (b) blue circles highlight $\mathrm{KCl}$ regions not connected to the original lamellae. In (d) blue circles highlight lamellae curving around holes formed by contact points between template spheres. In (f) blue circles highlight lamellae that change orientation as they wrap around holes at contact points.

Characterization: SEM was performed using Hitachi S-4700 and Hitachi S-4800 SEMs. Elemental mappings were carried out using the Hitachi S-4700 with an Oxford INCA EDX analyzer. Reflectance spectra were collected from an $\approx 250 \mu \mathrm{m}$ diameter spot on the sample using a Vertex $70 \mathrm{FTIR}$ and a Bruker Hyperion microscope. The reflectance from 1.0 to $3.0 \mu \mathrm{m}$ was collected using a $10 \times$ glass microscope objective (numerical aperture $=0.25$ ), a quartz beam splitter, and a liquidnitrogen-cooled InSb detector. Transmittance properties were measured using a Varian Cary 5G UV-vis-NIR spectrophotometer at room temperature, over the wavelength range of $200 \mathrm{~nm}$ to $1.8 \mu \mathrm{m}$. A Philips X'pert MRD XRD with $\mathrm{Cu} \mathrm{K}_{\alpha}$ radiation (1.5418 $\AA$ ) was used for X-ray diffraction experiments. The observed XRD peaks were compared with the Joint Committee on Powder Diffraction Standards (JCPDS).

FDTD Simulations: The photonic crystals were computationally studied using the FDTD method (see other sources ${ }^{[39,40]}$ for a description of FDTD) using MEEP. The refractive indices of $\mathrm{KCl}$ and $\mathrm{AgCl}$ were set as 1.49 and 2.09. For Figure 1e, 20 layers of each phases were used. For Figure 4e, alternating $90 \mathrm{~nm} \mathrm{KCl}$ and $100 \mathrm{~nm} \mathrm{AgCl}$ layers embedded within a five-layer close-packed $6 \mu \mathrm{m}$ colloid diameter opal template were used. Simulations were cut off at $500 \mathrm{~nm}$, and a "quick scan simulation" was used for Figure $4 \mathrm{e}$, resulting in somewhat noisy data. A detailed simulation would have required greater than $30 \mathrm{~d}$.

Directional Solidification: The mixed $\mathrm{AgCl}-\mathrm{KCl}$ eutectic powder was placed on the top of the template and heated to $450^{\circ} \mathrm{C}$ for $60 \mathrm{~min}$ in the modified three-zone furnace in air. After achieving thermal equilibrium, the sample was pulled from the $450{ }^{\circ} \mathrm{C}$ zone (T1) to an $\approx 250{ }^{\circ} \mathrm{C}$ zone (T2) using the indicated pulling rate. The total distance the sample was pulled was $25 \pm 3 \mathrm{~cm}$. The temperature profile is shown in Figure S10 (Supporting Information). After solidification in the $250{ }^{\circ} \mathrm{C}$ zone, the sample was pulled rapidly into the room temperature zone (T3).

Phase Field Modeling: Solidification was simulated using the phase field model described in ref. [41], modified to include the template spheres using the smoothed boundary method (SBM). ${ }^{[42]}$ The phase of the system at each point is described by a set of nonconserved order parameters $p_{\alpha}, p_{\beta}$, and $p_{\mathrm{L}}$, which take the following values: solid $\mathrm{AgCl}$ ( $\alpha$ phase), $p_{\alpha}=1, p_{\beta}=0, p_{\mathrm{L}}=0$; solid $\mathrm{KCl}\left(\beta\right.$ phase), $p_{\alpha}=0, p_{\beta}=1, p_{\mathrm{L}}=$ 0 ; and liquid, $p_{\alpha}=0, p_{\beta}=0, p_{\mathrm{L}}=1$. The order parameters are constrained such that $p_{\alpha}+p_{\beta}+p_{\mathrm{L}}=1$ at each point. The Allen-Cahn equation describing the evolution of each order parameter $p_{\mathrm{i}}$ is:

$$
\begin{aligned}
\tilde{\tau}(\vec{p}) \frac{\partial p_{\mathrm{i}}}{\partial \tilde{t}}= & \tilde{\nabla}^{2} p_{\mathrm{i}} \\
& +\frac{2}{3}\left(-2 p_{\mathrm{i}}\left(1-p_{\mathrm{i}}\right)\left(1-2 p_{\mathrm{i}}\right)+\sum_{j \neq i} p_{\mathrm{j}}\left(1-p_{\mathrm{j}}\right)\left(1-2 p_{\mathrm{j}}\right)\right) \\
& +\left.\tilde{\lambda} \sum_{j} \frac{\partial g_{\mathrm{j}}}{\partial p_{\mathrm{i}}}\right|_{p_{\alpha}+p_{\beta}+p_{\mathrm{L}}=1}\left(\mu A_{\mathrm{j}}-B_{\mathrm{j}}\right)
\end{aligned}
$$

where $\tilde{\tau}$ is the relaxation time, $\tilde{\lambda}$ is a coupling constant, $\tilde{t}$ is the time (tildes denote dimensionless variables), $\mathrm{g}_{j}$ is an interpolating polynomial, and $A_{i}$ and $B_{i}$ define a parabolic free energy with respect to concentration for each phase, $f_{c, i}=\left(c-A_{i}\right)^{2} / 2+B_{i}$. Interfacial energies between all three phases were assumed to be isotropic and equal to one another. Further details of the Allen-Cahn equations are available in ref. [41].

The composition at each point evolves by the diffusion equation, which is rewritten as an evolution equation for the chemical potential $\mu$. The SBM was used to enforce a no-flux boundary condition at the interface between the template spheres and the remainder of the system. The location of the spheres in the fcc-ordered template is indicated by the value of a domain parameter, $\psi$, at each point. Inside the template spheres, $\psi=0$, while outside the spheres $\psi=1$. The interface between the spheres and the remainder of the system is represented by a smooth variation of $\psi$. To derive the SBM-modified evolution equation for $\mu$, Equation 4.2 of ref. [41] is multiplied on both sides by $\psi$, and the product rule of differentiation and no-flux boundary conditions is applied as in ref. [42], resulting in: 
Table 1. Quantities used in parameterizing the phase field simulations.

\begin{tabular}{lccc}
\hline Quantity & Symbol & Value & Reference \\
\hline Liquidus slope of $\alpha$ & $m_{\alpha}$ & $-542 \mathrm{~K} \mathrm{~mol}^{-1}$ & {$[43]$} \\
Liquidus slope of $\beta$ & $m_{\beta}$ & $837 \mathrm{~K} \mathrm{~mol}^{-1}$ & {$[43]$} \\
Eutectic temperature & $T_{\mathrm{E}}$ & $591.73 \mathrm{~K}$ & {$[43]$} \\
Eutectic composition & $C_{\mathrm{E}}$ & $29.5 \mathrm{~mol} \%$ & {$[43]$} \\
Composition of $\alpha$ at $T_{\mathrm{E}}$ & $C_{\alpha}$ & $0 \mathrm{~mol} \%$ & {$[43]$} \\
Composition of $\beta$ at $T_{\mathrm{E}}$ & $C_{\beta}$ & $100 \mathrm{~mol} \%$ & {$[43]$} \\
$\alpha$-Liquid interfacial energy & $\sigma_{\alpha \mathrm{L}}$ & $154 \mathrm{~mJ} \mathrm{~m}{ }^{-2}$ & Assume same as $\sigma_{\beta L}$ \\
$\beta$-Liquid interfacial energy & $\sigma_{\beta L}$ & $154 \mathrm{~mJ} \mathrm{~m}^{-2}$ & {$[44]$} \\
$\alpha-\beta$ Interfacial energy & $\sigma_{\alpha \beta}$ & $154 \mathrm{~mJ} \mathrm{~m}^{-2}$ & Assume same as $\sigma_{\beta L}$ \\
Latent heat of fusion per unit & $L_{\alpha}$ & $5.12 \times 10^{8} \mathrm{~J} \mathrm{~m}^{-3}$ & {$[45]$} \\
volume for $\alpha$ & & & {$[45]$} \\
Latent heat of fusion per unit & $L_{\beta}$ & $6.93 \times 10^{8} \mathrm{~J} \mathrm{~m}^{-3}$ & \\
volume for $\beta$ & & & {$[46]^{\mathrm{a})}$} \\
Diffusion coefficient & $D$ & $4.7 \times 10^{-10} \mathrm{~m}^{2} \mathrm{~s}^{-1}$ &
\end{tabular}

a) Because the diffusion coefficient at the eutectic temperature and composition has not been measured to our knowledge, the diffusion coefficient was estimated from the diffusivity of dilute $\mathrm{K}^{+}$in liquid $\mathrm{AgCl}$, adjusted to the eutectic temperature using the prefactor and activation energy given in ref. [46].

$$
\begin{aligned}
\frac{\partial \mu}{\partial \tilde{t}}= & \frac{1}{\psi} \tilde{\nabla} \cdot\left(\psi \tilde{D} p_{L} \tilde{\nabla} \mu\right)-\frac{\tilde{\nabla} \psi \cdot \vec{j}_{a t}}{\psi} \\
& -\sum_{i} A_{i} \frac{\partial p_{i}}{\partial \tilde{t}}+2 a \sum_{i=\alpha, \beta}\left(A_{i}-A_{L}\right)\left(-\hat{n}_{L} \cdot \hat{n}_{i}\right) \tilde{\nabla} \cdot\left(\hat{n}_{i} \frac{\partial p_{i}}{\partial \tilde{t}}\right)
\end{aligned}
$$

where $\tilde{D}$ is the dimensionless diffusion coefficient, $\vec{J}_{\text {at }}$ is the antitrapping current described in ref. [41], $a$ is a constant, and $\widehat{n_{i}}$ is the interfacial normal vector for phase $\mathrm{i}$.

The physical parameters used to simulate the $\mathrm{AgCl}-\mathrm{KCl}$ system are shown in Table 1. A 1D model based on the heat conduction equation for the experimental samples showed that there was minimal temperature variation within the sample during cooling over the length scale (the domain size) simulated by the phase field model. Therefore, we assume that temperature is uniform throughout the simulation volume and decreases at a constant rate $R$.

In the phase field model, solidification is driven by changes in the free energies of each phase (parameterized by $A_{\mathrm{i}}$ and $B_{\mathrm{i}}$ ) as a function of temperature. Because only relative free energy differences between phases are physically meaningful, we set $A_{L}=B_{L}=0$. The $\mathrm{AgCl}-\mathrm{KCl}$ phase diagram indicates that there is negligible solubility of $\mathrm{KCl}$ in solid $\mathrm{AgCl}$ and vice versa, so the parameterization of $A_{\alpha}, B_{\alpha}, A_{\beta}$, and $B_{\beta}$ differs from that presented in ref. [41]. Concentrations are non-dimensionalized as in ref. [41]:

$c=\frac{C-C_{E}}{\Delta C}$

where $c$ is the (dimensionless) scaled concentration, $C$ the concentration of $\mathrm{KCl}$ in mol\%, $C_{E}$ the concentration at the eutectic point, and $\Delta C=C_{\beta}-C_{\alpha}$ the difference in concentrations between the solid phases $\alpha$ and $\beta$. The dimensionless concentrations of $\mathrm{KCl}$ in each solid phase, $c_{\alpha}$ and $c_{\beta}$, are independent of temperature. Using the common tangent construction, a form for the $A_{i}$ and $B_{i}$ coefficients was derived that reproduces the $\mathrm{AgCl}-\mathrm{KCl}$ phase diagram and that causes the temperature to decrease uniformly throughout the system at constant rate $R$ :

$A_{\mathrm{i}}=c_{\mathrm{i}}-\frac{\Delta T+\tilde{R} \tilde{t}}{m_{\mathrm{i}} \Delta C}$
$B_{\mathrm{i}}=A_{\mathrm{i}} \frac{\Delta T+\tilde{R} \tilde{t}}{m_{\mathrm{i}} \Delta C}$

where $m_{\mathrm{i}}$ is the liquidus slope of phase $\mathrm{i}$ and $\Delta T$ is the initial undercooling.

The phase field model was discretized using a centered finite difference scheme with forward Euler explicit time steps. The governing equations were non-dimensionalized as in ref. [25], with characteristic length $W=10^{-8} \mathrm{~m}$ and characteristic time $3.4 \times 10^{-6} \mathrm{~s}$. The dimensionless grid spacing was set to $\Delta \tilde{x}=0.8$, and dimensionless time step was $\Delta \tilde{t}=4.0 \times 10^{-3}$. No-flux boundary conditions were used parallel to the solidification direction $(\gamma)$, and periodic boundary conditions were used in directions perpendicular to the solidification direction $(x$ and $z$ ). The code was parallelized using the message passing interface (MPI) library, and run on 160-640 cores depending on the system size.

In the initial conditions, the solid-liquid interface was positioned at a distance equal to the lamellar pitch from the boundary of the template region. On the solid side of the interface (away from the template) were one, two, or three complete periods of lamellar solid (depending on sphere diameter). The lamellar pitch was set to $640 \mathrm{~nm}$ as measured experimentally. The simulation volume on the liquid side of the interface, including the interstitial voids between the template particles, was filled with liquid at the eutectic composition. Because the current phase field model does not account for differences in molar volume between the three phases, the volume fraction of the solid phases in simulation is $70 \% \mathrm{AgCl} / 30 \% \mathrm{KCl}$ (equal to the molar composition), rather than $62 \%$ $\mathrm{AgCl} / 38 \% \mathrm{KCl}$ as measured experimentally. The cooling rate $R$ was set to $5 \mathrm{~K} \mathrm{~min}^{-1}$, which is similar to the experimental value of about $7 \mathrm{~K} \mathrm{~min}^{-1}$.

\section{Supporting Information}

Supporting Information is available from the Wiley Online Library or from the author.

\section{Acknowledgements}

This work was supported by the Air Force Office of Scientific Research (AFOSR) MURI FA9550-08-1-0407.

Received: May 12, 2015

Revised: June 8, 2015

Published online: July 14, 2015

[1] C. Zhang, M. D. Losego, P. V. Braun, Chem. Mater. 2013, 25, 3239.

[2] C. Zhang, G. G. Cano, P. V. Braun, Adv. Mater. 2014, 26, 5678.

[3] A. Mihi, H. Miguez, I. Rodriguez, S. Rubio, F. Meseguer, Phys. Rev. B 2005, 71, 125131

[4] A. Mihi, H. Miguez, J. Phys. Chem. B 2005, 109, 15968.

[5] A. Mihi, M. E. Calvo, J. A. Anta, H. Miguez, J. Phys. Chem. C 2008, 112, 13.

[6] E. C. Nelson, N. L. Dias, K. P. Bassett, S. N. Dunham, V. Verma, M. Miyake, P. Wiltzius, J. A. Rogers, J. J. Coleman, X. L. Li, P. V. Braun, Nat. Mater. 2011, 10, 676

[7] N. Liu, L. W. Fu, S. Kaiser, H. Schweizer, H. Giessen, Adv. Mater. 2008, 20, 3859.

[8] T. Buckmann, N. Stenger, M. Kadic, J. Kaschke, A. Frolich, T. Kennerknecht, C. Eberl, M. Thiel, M. Wegener, Adv. Mater. 2012, 24, 2710.

[9] S. Jeon, E. Menard, J. U. Park, J. Maria, M. Meitl, J. Zaumseil, J. A. Rogers, Adv. Mater. 2004, 16, 1369.

[10] T. Y. Chan, O. Toader, S. John, Phys. Rev. E 2006, 73, 046610. 
www.MaterialsViews.com

[11] A. Blanco, E. Chomski, S. Grabtchak, M. Ibisate, S. John S. W. Leonard, C. Lopez, F. Meseguer, H. Miguez, J. P. Mondia G. A. Ozin, O. Toader, H. M. van Driel, Nature 2000, 405, 437.

[12] P. V. Braun, Chem. Mater. 2014, 26, 277.

[13] B. H. Cumpston, S. P. Ananthavel, S. Barlow, D. L. Dyer, J. E. Ehrlich, L. L. Erskine, A. A. Heikal, S. M. Kuebler, I. Y. S. Lee, D. McCord-Maughon, J. Q. Qin, H. Rockel, M. Rumi, X. L. Wu, S. R. Marder, J. W. Perry, Nature 1999, 398, 51.

[14] J. Fischer, J. B. Mueller, J. Kaschke, T. J. A. Wolf, A. N. Unterreiner, M. Wegener, Opt. Express 2013, 21, 26244.

[15] G. M. Gratson, M. Xu, J. A. Lewis, Nature 2004, 428, 386

[16] G. M. Gratson, F. Garcia-Santamaria, V. Lousse, M. J. Xu, S. H. Fan, J. A. Lewis, P. V. Braun, Adv. Mater. 2006, 18, 461

[17] S. A. Rinne, F. Garcia-Santamaria, P. V. Braun, Nat. Photonics 2008 , 2, 52.

[18] S. G. Park, M. Miyake, S. M. Yang, P. V. Braun, Adv. Mater. 2011, 23, 2749.

[19] J. Kim, H. S. Kim, J. H. Choi, H. Jeon, Y. Yoon, J. Liu, J.-G. Park, P. V. Braun, Chem. Mater. 2014, 26, 7051.

[20] J. D. Hunt, K. A. Jackson, Trans. Metall. Soc. AIME 1966, 236, 843.

[21] K. A. Jackson, J. D. Hunt, Trans. Metall. Soc. AIME 1966, 236, 1129.

[22] J. D. Hunt, K. A. Jackson, Trans. Metall. Soc. AIME 1967, 239, 864.

[23] K. Lambrinou, O. Van der Biest, J. Eur. Ceram. Soc. 2007, 27, 1805.

[24] P. B. Oliete, J. I. Pena, A. Larrea, V. M. Orera, J. LLorca, J. Y. Pastor, A. Martin, J. Segurado, Adv. Mater. 2007, 19, 2313.

[25] H. Bei, E. P. George, Acta Mater. 2005, 53, 69.

[26] D. A. Pawlak, G. Lerondel, I. Dmytruk, Y. Kagamitani, S. Durbin, P. Royer, T. Fukuda, J. Appl. Phys. 2002, 91, 9731.

[27] R. I. Merino, J. I. Peña, Á. Larrea, G. F. Fuente, V. M. Orera, Recent Res. Dev. Mater. Sci. 2003, 4, 1.
[28] D. A. Pawlak, K. Kolodziejak, S. Turczynski, J. Kisielewski, K. Rozniatowski, R. Diduszko, M. Kaczkan, M. Malinowski, Chem. Mater. 2006, 18, 2450.

[29] D. A. Pawlak, S. Turczynski, M. Gajc, K. Kolodziejak, R. Diduszko, K. Rozniatowski, J. Smalc, I. Vendik, Adv. Funct. Mater. 2010, 20, 1116.

[30] K. Sadecka, M. Gajc, K. Orlinski, H. B. Surma, A. Klos, I. Jozwik-Biala, K. Sobczak, P. Dluzewski, J. Toudert, D. A. Pawlak, Adv. Opt. Mater. 2015, 3, 381.

[31] P. D. Garcia, R. Sapienza, J. Bertolotti, M. D. Martin, A. Blanco, A. Altube, L. Vina, D. S. Wiersma, C. Lopez, 023823 Phys. Rev. A 2008, 78.

[32] P. D. Garcia, R. Sapienza, C. Lopez, Adv. Mater. 2010, 22, 12.

[33] V. M. Orera, J. I. Pena, M. A. Laguna-Bercero, R. I. Merino, A. Larrea, G. Garcia, A. Figueras, Ceram. Eng. Sci. Proc. 2003, 24, 181.

[34] A. Chandra, A. Spangenberg, J. Maier, J. Electroceram. 1999 $3,47$.

[35] Y. Kang, J. J. Walish, T. Gorishnyy, E. L. Thomas, Nat. Mater. 2007, $6,957$.

[36] H. T. Yang, P. Jiang, Langmuir 2010, 26, 13173.

[37] R. L. Ashbrook, J. Am. Ceram. Soc. 1977, 60, 428

[38] W. Stober, A. Fink, E. Bohn, J. Colloid Interface Sci. 1968, 26, 62.

[39] E. K. Miller, IEEE Trans. Antennas Propag. 1988, 36, 1281.

[40] A. Taflove, S. C. Hagness, M. Piket-May, Electrical Engineering Handbook, Elsevier, New York 2005, p. 629.

[41] R. Folch, M. Plapp, Phys. Rev. E 2005, 72, 11602.

[42] H. C. Yu, H. Y. Chen, K. Thornton, Model. Simul. Mater. Sci. 2012, 20, 75008

[43] E. Fischer, J. Phase Equilib. 2003, 24, 228

[44] P. C. R. Rodrigues, F. M. S. S. Fernandes, Eur. Phys. J. D 2006, 40, 115.

[45] A. D. Pelton, W. T. Thompson, Can. J. Chem. 1970, 48, 1585.

[46] G. J. Janz, N. P. Bansal, J. Phys. Chem. Ref. Data 1982, 11, 505. 